\title{
Optimal Efficiency Control of PM Hybrid Motor Drives for Electrical Vehicles
}

\author{
C. C. Chan, Ruoju Zhang, K. T. Chau \\ Department of Electrical \& Electronic Engineering \\ The University of Hong Kong \\ J. Z. Jiang \\ College of Automatic Control Engineering \\ Shanghai University
}

\begin{abstract}
The paper deals with the control of a novel brushless PM hybrid motor to optimize its efficiency. The approach is to adaptively adjust the field current to minimize the total loss based on its potential for a high efficiency over a wide torque-speed region. The optimal controller has good performance for electrical vehicles.
\end{abstract}

\section{INTRODUCTION}

Modern electrical vehicles (EVs) require the motor drives with high efficiency, high power density, efficient regenerative braking, wide speed range, high controllability, robustness, reliable and maintenance free $\mathrm{e}^{[1][2]}$. To develop an advanced motor drive system that possesses both the DC motor drive advantage of a quality speed control and the $\mathrm{AC}$ motor drive advantages of high reliability, robustness and almost maintenance free is our research goal. In recent years, the International Research Center for Electrical Vehicles (IRCEV) in the University of Hong Kong has launched to design an efficient AC motor and its drive system for EV applications. The permanent magnet hybrid motor (PMHM) and its drive system are specially designed to satisfy the EV requirements.

As compared with the induction motor, the permanent magnet (PM) motor possesses some distinct advantages such as high power density, high efficiency and better controllability. However, the field of the PM motor can not be readily weakened for wide constant-power operation range, while constant-torque operation can be easily achieved in any PM motor drive system, since magnet can maintain an almost constant airgap flux. For EV applications, the traction load requires a constant-torque drive to rated speed, and a constant-power operation at higher speed, which is shown in Fig. 1. To meet these requirements, the PMHM, which is shown in Fig. 2, has been developed by employing a new exciting system ${ }^{[3]}$. The excitation of PMHM comprises of both the permanent magnets and a field winding. By adjusting the field current in the additional stationary field winding, the flux weakening can be achieved easily. Due to the existence of both the permanent magnets and the field winding, the PMHM is designed to achieve higher airgap flux density and higher power density. Another significant function for the field winding is to optimize the efficiency and power factor of the PMHM, so the motor torque speed characteristic can be readily regulated to meet the load demand with high efficiency for a wide speed range. In motors for EVs, efficiency is regard as an important factor. In order to increase the drive range, optimal efficiency operation particularly is necessary in the light-load and high-speed operation ranges.

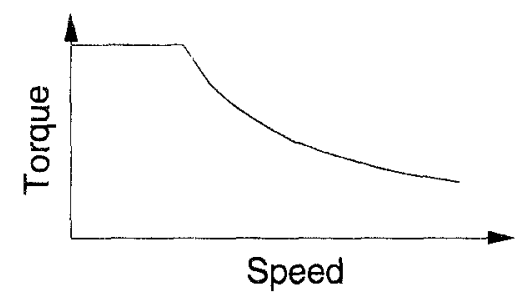

Fig. 1. Torque speed characteristics of electrical vehicle.

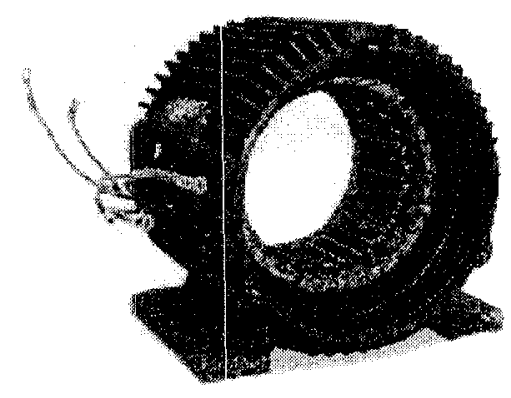

(a) Stator of PMHM.

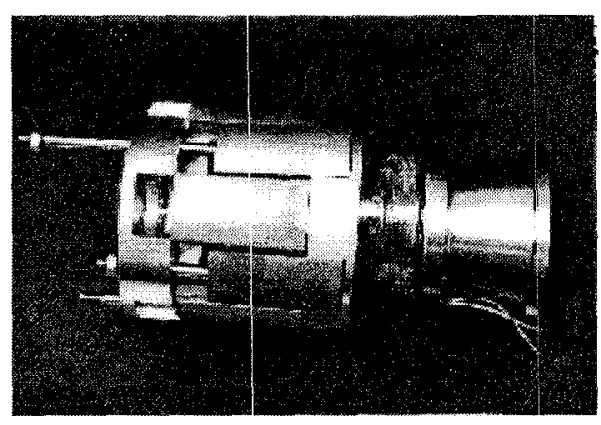

(b) Fotor of PMHM.

Fig. 2. Construction of the PMHM. 
The purpose of this paper is to present an optimal efficiency control scheme for the PMHM drive system throughout the whole operation region. The key is by adjusting the field current to minimize the total losses for a given operation speed and torque requirement. In Section II, the PMHM model is described. The proposed optimal efficiency control scheme is detailed in Section III. The implementation and result are given in Section IV.

\section{PMHM MODEL}

The PMHM shares the basic characteristics of the PM brushless motor such as high efficiency and high power density, in addition, it overcomes the major drawback of the constant flux of the PM brushless motors by using an additional stationary winding.

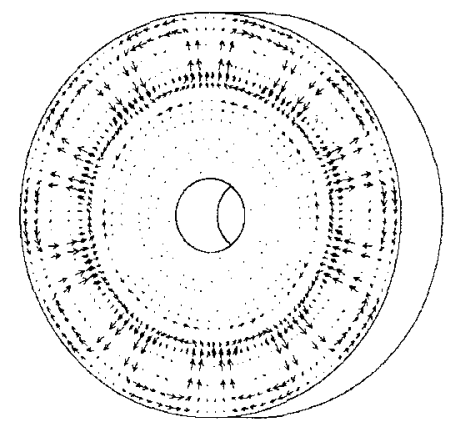

(a) Radial flux density.

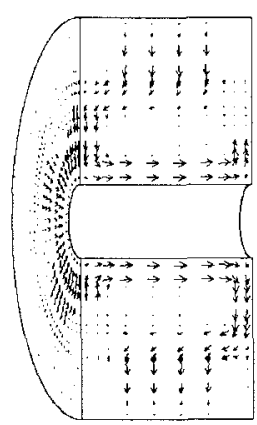

(b) Axial flux density.

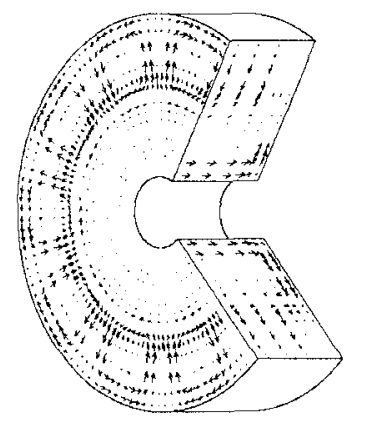

(c) Radial and axial flux density.

Fig. 3. Magnetic flux density distribution.
The stator of the PMHM is similar to a normal three-phase AC motor stator, while the rotor adopts the claw type construction, which mainly comprises of permanent magnets and a stationary field winding to provide airgap flux. Due to the novel configuration of the PMHM, shown in Fig. 2, its magnetic field distribution is three-dimensional. The design and optimization of the PMHM adopts three-dimension (3-D) finite element network method. The magnetic flux density $\bar{B}$ distribution, calculated by using 3-D finite element network method, is shown in Fig. 3, where the $\bar{B}$ vector arrow represents both the direction and the relative magnitude of the flux density. It should be noted that the magnetomotive forces produced by the permanent magnets and by the stationary field winding are magnetically shunt in nature.

According to field analysis, the mathematical model of the PMHM is established. The following discussion of the PMHM is based on the familiar $\mathrm{d}-\mathrm{q}$ axis model of a salient pole synchronous machine in the rotor reference frame. Using of this model requires adoption of a set of standard assumptions, including:

(a) Magnetic saturation is neglected.

(b) The stator has sinusoidal winding distribution, and the stator current produces only the sinusoidal flux inside the airgap while neglecting the higher order components.

(c) The three stator windings are all identical and the electrical angle between two phases is $120^{\circ}$.

(d) The no load emf of the stator is sinusoidal so that the mutual inductance between stator and rotor is a sinusoidal function of $\theta$.

(e) Because of the linear $\mathrm{B}-\mathrm{H}$ characteristic of the latest high energy PM materials, which is shown in Fig. 4 (a), the magnet can be modeled as a magnetomotive force (MMF) source $F_{p m}$ in series with a linear reluctance $R_{p m}$ as in Fig. 4 (b). For a magnet material with coercive force $H_{c}$ and a linear characteristic throughout the second $B-H$ quadrant, the magnet MMF is $F_{p m}=H_{c} l_{p m}$, where $l_{p m}$ is the width of the magnet. The current source of magnet $i_{p m}$ is evaluated as:

$$
i_{p m}=k_{W} H_{c} l_{p m}
$$

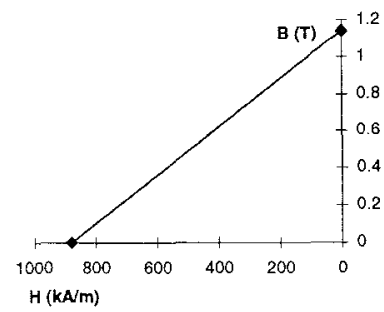

(a)

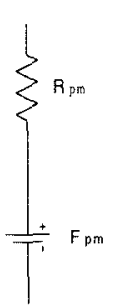

(b)
Fig. 4. Demagnetization characteristic of NdFeB. 
Hence, the system model equations are given as:

$$
\left[\begin{array}{c}
U_{d} \\
U_{q} \\
U_{f} \\
E_{p m}
\end{array}\right]=\left([R]+[L] p+[G] \omega_{r}\right)\left[\begin{array}{c}
i_{d} \\
i_{q} \\
i_{f} \\
i_{p m}
\end{array}\right]
$$

where

$$
\begin{aligned}
& {[R]=\left[\begin{array}{cccc}
r_{s} & 0 & 0 & 0 \\
0 & r_{s} & 0 & 0 \\
0 & 0 & r_{f} & 0 \\
0 & 0 & 0 & r_{p m}
\end{array}\right]} \\
& {[L]=\left[\begin{array}{cccc}
L_{d} & 0 & L_{s f} & 0 \\
0 & L_{q} & 0 & 0 \\
L_{f s} & 0 & L_{f} & 0 \\
0 & 0 & 0 & 0
\end{array}\right]} \\
& {[G]=\left[\begin{array}{cccc}
0 & -L_{q} & 0 & 0 \\
L_{d} & 0 & L_{s f} & L_{s p m} \\
0 & 0 & 0 & 0 \\
0 & 0 & 0 & 0
\end{array}\right]}
\end{aligned}
$$

With the introduction of the fictitious resistance $r_{p m}$, the permanent magnet is represented by the equivalent current $i_{p m}$, whose value is defined by the excitation voltage $E_{p m}$ as:

$$
E_{p m}=r_{p m} i_{p m}=\frac{1}{\sqrt{3}} \omega_{r} L_{s p m} i_{p m}
$$

Hence, the electromagnetic torque with $n_{p}$ pole pairs is:

$$
T_{e}=n_{p}\left[\begin{array}{llll}
i_{d} & i_{q} & i_{f} & i_{p m}
\end{array}\right]\left[\begin{array}{c}
i_{d} \\
i_{q} \\
i_{f} \\
i_{p m}
\end{array}\right]
$$

The equation of motion is expressed as:

$$
\frac{J}{n_{p}} p \omega_{r}+\frac{D}{n_{p}} \omega_{r}=T_{e}-T_{l}
$$

where $D$ is friction coefficient, $J$ is the moment of inertia

The new construction of the PMHM gives the control system an additional control variable, the field current $i_{f}$. The efficiency of PMHM can be optimized for a fixed power and speed by adaptively adjusting its terminal voltage and field current throughout its operating range, which is given as $^{[3][4] \text { : }}$

$$
\eta=\max \left\{\eta\left(U, E_{f}\right) \delta \leq 30^{\circ}, P=\text { Const }, \omega=\text { Const }\right\}
$$

\section{PMHM DRIVE SYSTEM}

The PMHM main circuit is shown in Fig. 5. The third generation IGBT intelligent power module PM100RSA60, consisting of seven power electronic devices, is chosen as the voltage source inverter. The inverter is designed to drive the proposed PMHM ranging from $2-800 \mathrm{~Hz}$ with a frequency step of $0.125 \mathrm{~Hz}$. The PWM pattern adopts the voltage space vector modulation and is calculated in real time. The significant advantages of the space vector modulation are the ease of microprocessor implementation, and the waveforms produced are very nearly loss minimized ${ }^{[5]}$.

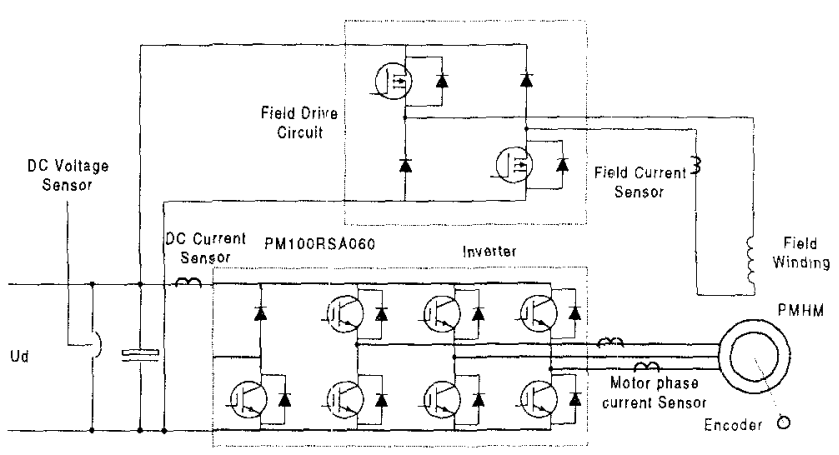

Fig. 5. PMHM drive system main circuit.

There is a field drive circuit in the PMHM drive system, which is specially design to drive the PMHM field current to achieve the flux-weakening operation for the whole drive system.

This drive system provides feedbacks including DC voltage, DC current, motor phase current, speed and rotor position. The fault signals, comprising of DC under voltage, DC over voltage, DC over current, motor over current, IGBT module fault, motor over temperature and inverter over temperature, are detected to prevent the system from abnormal operation.

The block diagram for the speed control system of the PMHM for optimal efficiency operation is illustrated in Fig. 6 . This control system incorporates a new fuzzy controller into the vector controller based on the specification of the PMHM. A PI controller: component is included so as to determine the operating reference torque value $T^{*}$. Based on the motor speed $\omega$ and operating torque reference $T^{*}$, the fuzzy logic controller is used to adjust the field current $I_{j}$ and to estimate the airgap flux $\varphi^{*}$ of the PMHM hence controlling the motor operating at the optimal efficiency point. The vector controller controls the magnetizing 
component and torque component independently in order to achieve the high performance operation.

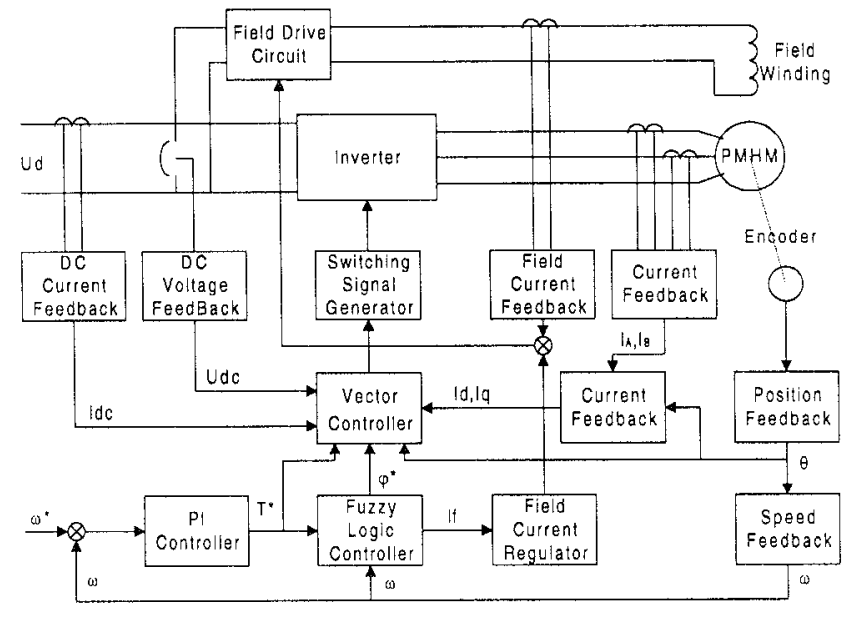

Fig. 6. Block diagram for the control system of PMHM.

A fuzzy set for optimal efficiency control is defined. The fuzzy logic controller is designed to have two fuzzy state variables and two control variables to achieve maximum efficiency control.

The first variable is the difference between the command speed and the base speed.

$E_{\omega}=\omega^{*}-\omega_{N}$

The universe of discourse of the speed error fuzzy variable is divided into seven overlapping fuzzy sets: Positive Large error (PLs), Positive Middle error (PMs), Positive Small error (PSs), Zero error (Zs), Negative Small error (NSs), Negative Middle error (NMs), and Negative Large error (NLs). The grade of membership distribution is given in Fig. 7 (a), which uses a triangular distribution.

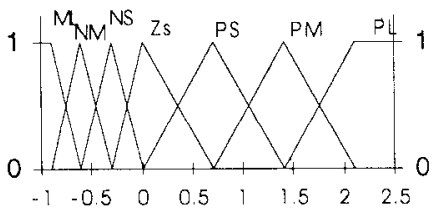

(a) Speed error.

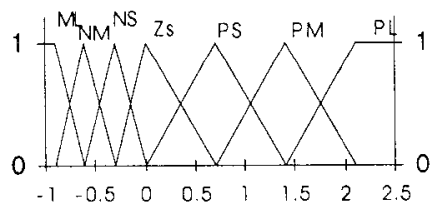

(b) Torque error

Fig. 7. Membership distribution of fuzzy variables.

The second fuzzy state variable is the difference between the estimated motor torque and the base torque:
$E_{T}=T_{e}-T_{N}$

.The universe of discourse of the torque error fuzzy variable is divided into seven overlapping fuzzy sets: Positive Large error $\left(\mathrm{PL}_{\mathrm{T}}\right)$, Positive Middle error $\left(\mathrm{PM}_{\mathrm{T}}\right)$, Positive Small error $\left(\mathrm{PS}_{\mathrm{T}}\right)$, Zero error $\left(\mathrm{Z}_{\mathrm{T}}\right)$, Negative Small error $\left(\mathrm{NS}_{\mathrm{T}}\right)$, Negative Middle error $\left(\mathrm{NM}_{\mathrm{T}}\right)$, and Negative Large error $\left(\mathrm{NL}_{\mathrm{T}}\right)$. The grade of membership distribution is shown in Fig. 7 (b). The motor torque is estimated from the PI controller.

The control variables are the field current $I_{f}$ and estimated airgap flux $\varphi^{*}$. Each control rule can be described using the state variables $E_{s}$ and $E_{T}$, as well as control variables $i_{f}$ and $\varphi^{*}$. The i rule $R_{i}$ can be written as:

$$
\begin{aligned}
& R_{i}: \text { if } E_{s} \text { is } A_{i} \text {, and } E_{T} \text { is } B_{i} \\
& \text { then } i_{f} \text { is } C_{i} \text {, and } \varphi^{*} \text { is } D_{i} .
\end{aligned}
$$

Where $A_{i}, B_{i}, C_{i}$ and $D_{i}$ represent the fuzzy segments

TABLE I

FUZZY CONTROLLER LOOK-UP TABLE FOR $i_{f}$

\begin{tabular}{|l|l|l|l|l|l|l|l|}
\hline$E_{\mathrm{\omega}} \backslash \mathrm{E}_{\mathrm{T}}$ & $\mathrm{NL}_{\mathrm{T}}$ & $\mathrm{NM}_{\mathrm{T}}$ & $\mathrm{NS}_{\mathrm{T}}$ & $\mathrm{Z}_{\mathrm{T}}$ & $\mathrm{PST}$ & $\mathrm{PM}_{\mathrm{T}}$ & $\mathrm{PL}_{\mathrm{T}}$ \\
\hline $\mathrm{NLs}$ & 0.55 & 1.0 & 1.0 & 1.0 & 1.0 & 1.0 & 1.0 \\
\hline $\mathrm{NMs}$ & 0.325 & 0.785 & 1.0 & 1.0 & 1.0 & 1.0 & 1.0 \\
\hline $\mathrm{NSs}$ & 0.225 & 0.375 & 0.965 & 1.0 & 1.0 & 1.0 & 1.0 \\
\hline $\mathrm{Zs}$ & 0.15 & 0.60 & 0.875 & 1.0 & 1.0 & 1.0 & 1.0 \\
\hline PSs & 0.0 & 0.25 & 0.50 & 0.625 & 0.825 & 1.0 & 1.0 \\
\hline PMs & 0.0 & 0.1 & 0.275 & 0.45 & 0.625 & 0.925 & 1.0 \\
\hline PLs & 0.0 & 0.05 & 0.20 & 0.425 & 0.650 & 0.89 & 0.975 \\
\hline
\end{tabular}

TABLE II

FuzZy CONTROLLER LOOK-UP TABLE For $\varphi^{*}$

\begin{tabular}{|l|l|l|l|l|l|l|l|}
\hline $\mathrm{E}_{\mathrm{w}} \mathrm{E}_{\mathrm{T}}$ & $\mathrm{NL}_{\mathrm{T}}$ & $\mathrm{NM}_{\mathrm{T}}$ & $\mathrm{NS}_{\mathrm{T}}$ & $\mathrm{Z}_{\mathrm{T}}$ & $\mathrm{PST}$ & $\mathrm{PM}_{\mathrm{T}}$ & $\mathrm{PL}_{\mathrm{T}}$ \\
\hline $\mathrm{NLs}$ & 0.602 & 0.833 & 1.0 & 1.0 & 1.0 & 1.0 & 1.0 \\
\hline $\mathrm{NMs}$ & 0.445 & 0.679 & 0.856 & 0.955 & 1.0 & 1.0 & 1.0 \\
\hline $\mathrm{NSs}$ & 0.407 & 0.606 & 0.795 & 0.883 & 0.966 & 1.0 & 1.0 \\
\hline $\mathrm{Zs}$ & 0.384 & 0.6 & 0.756 & 0.847 & 0.927 & 1.0 & 1.0 \\
\hline $\mathrm{PSs}$ & 0.305 & 0.439 & 0.561 & 0.629 & 0.691 & 0.84 & 1.0 \\
\hline $\mathrm{PMs}$ & 0.297 & 0.364 & 0.464 & 0.555 & 0.686 & 0.893 & 1.0 \\
\hline $\mathrm{PLs}$ & 0.293 & 0.323 & 0.429 & 0.523 & 0.668 & 0.875 & 0.988 \\
\hline
\end{tabular}

According to the simulation and experimental results, the look-up tables of $i_{f}$ and $\varphi^{*}$ are created as in Table I and Table II respectively. The interface method used is basic and simple. The output of the fuzzy controller is a nonfuzzy value, and the final combined fuzzy set is defined by the 
union of all rule output fuzzy sets using the maximum aggregation method ${ }^{[6]}$.

\section{RESULT}

The PMHM uses an additional stationary field winding to adjust the airgap flux. Fig. 8 is the experimental results to show the influence of the field current. The back EMF $E_{p m}$ while $i_{f}=0$ is given in Fig. 8 (a). It can be noted that the flux distribution is almost sinusoidal. Fig. 8 (b) shows the flux-weakening specification of the PMHM. The fluxweakening is readily achieved by changing the field winding current for the PMHM.

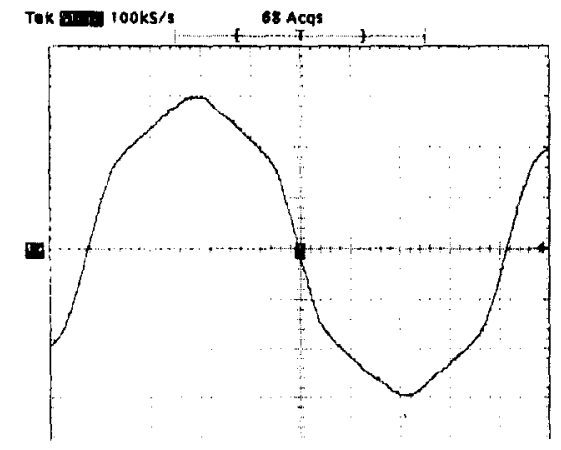

(a) Back EMF $E_{p m}\left(I_{f}=0, n=1000 \mathrm{rpm}\right)$.

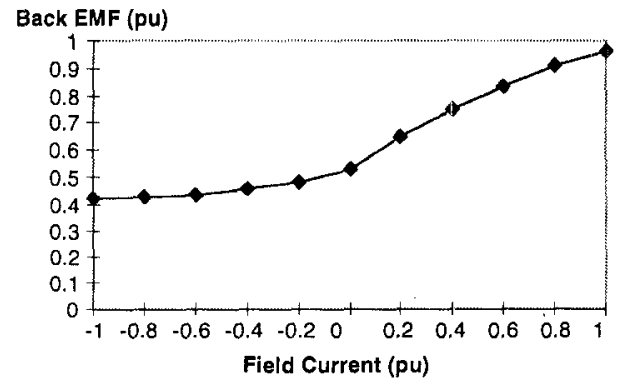

(b) Flux-weakening curve

Fig. 8. Field weakening of PMHM.

The topology of the motor and its drive system are designed to maximize the overall system efficiency. For the EV application, the controller main functions focus on the acceleration, deceleration (regenerative braking), and optimal efficiency operation. The efficiency optimization control strategy is implemented on a microprocessor based system. The system is assumed to operate under a uniform sample rate. In each sample period, the error between the reference speed $\omega^{*}$ and the feedback motor speed $\omega$ is processed by a digital PI controller that generates the reference torque $T^{*}$. After the generation of the reference torque $T^{*}$, the fuzzy logic controller is chosen to determine the reference current $i_{f}{ }^{*}$ and airgap flux $\varphi^{*}$. The vector controller generates the terminal voltage, using the space vector modulation, and the switching signals are produced to control the inverter. The simulation flowchart of the PMHM drive system is shown in Fig. 9.

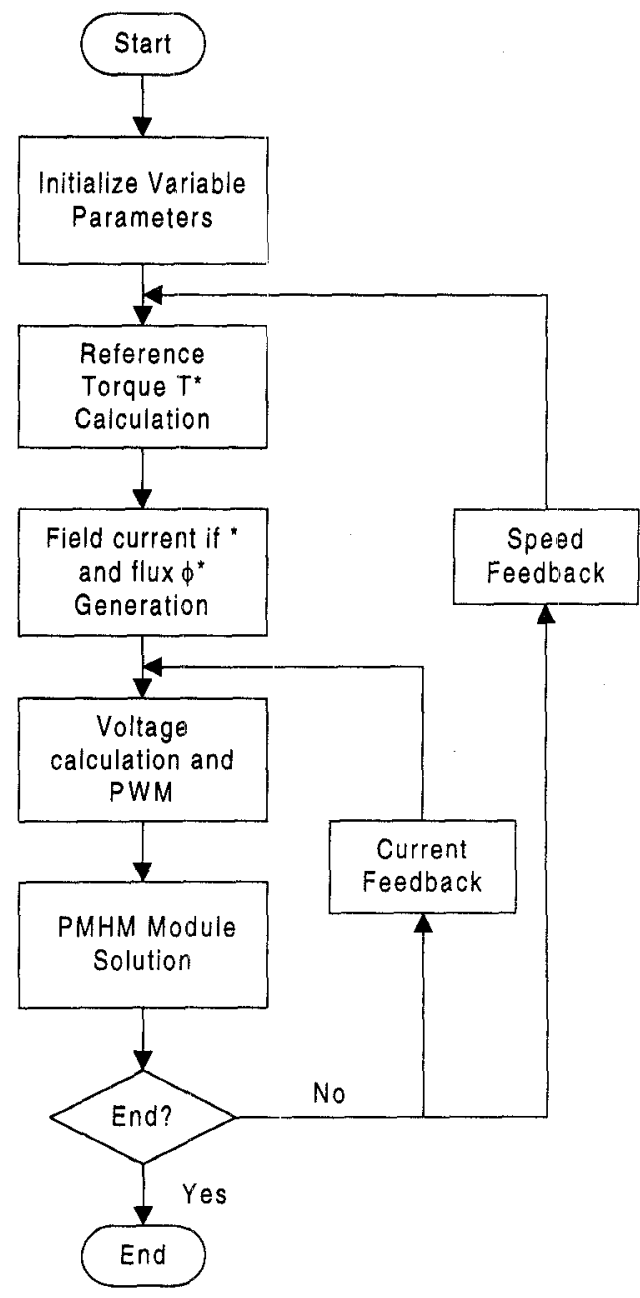

Fig. 9. Sirnulation flowchart.

The actual parameters of an experimental PMHM are used to simulate the entire drive system. A typical steady state phase current waveform is shown in Fig. 10.

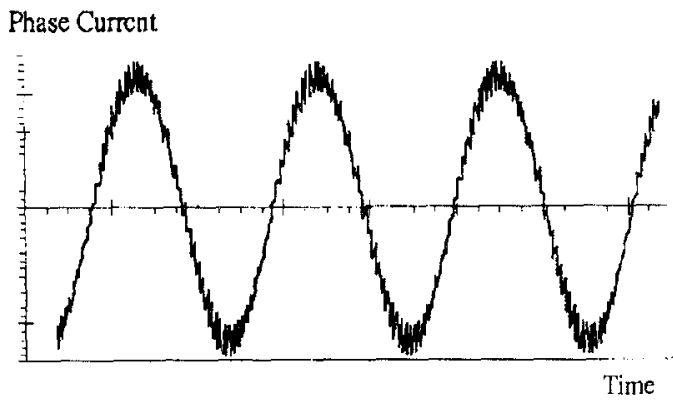

Fig. 10. Phase current waveform.

The dynamic performance of the overall PMHM drive system 
is shown in Fig. 11. Fig. 11 (a) is the speed response at startup $(t=0)$, and at sudden load increase $(t=0.8 s)$. Fig. $11(b)$ is the corresponding motor torque.

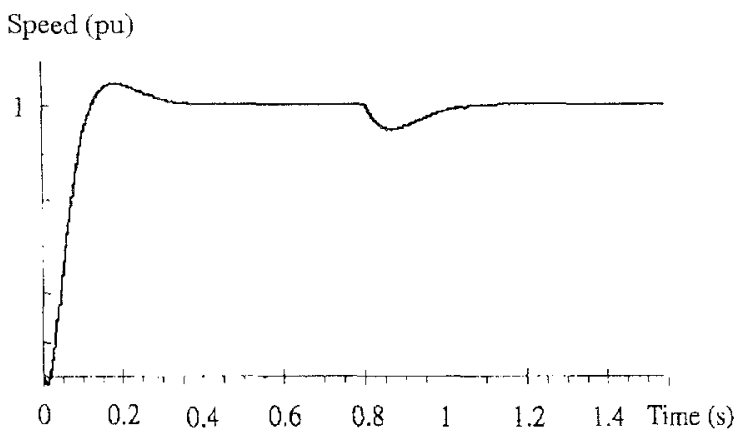

(a) Speed response.

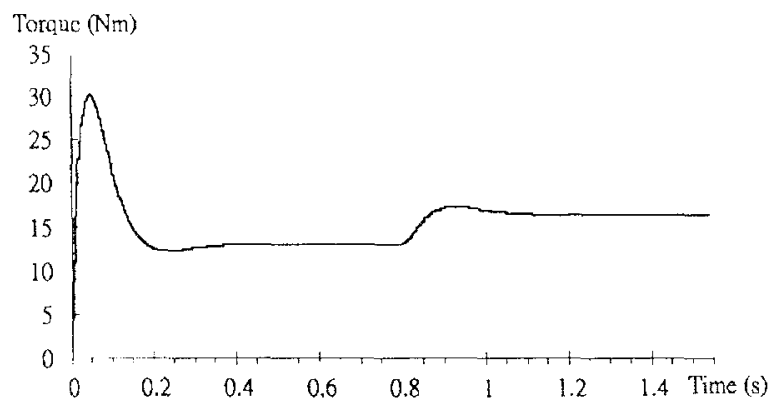

(b) Torque response

Fig. 11. Simulated transient responses

In order to achieve high efficiency operation, the airgap flux should be weakened for the low-torque operation in constant torque operation and high-speed operation in the constant power region. The efficiency profile of the PMHM throughout its operating range can be obtained as shown in the Fig. 12 .

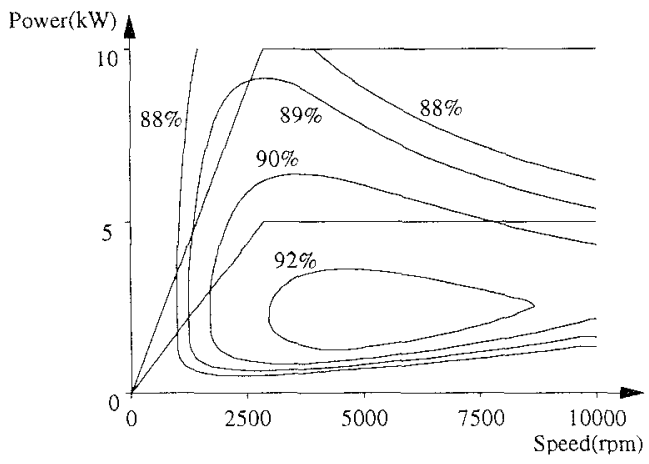

Fig. 12. The efficiency profile of the PMHM.

\section{Conclusion}

A novel brushless permanent magnet hybrid motor and its drive system have been developed. This motor not only possesses the advantages of high efficiency and high power density but also provides wide speed range for constant power operation. By employing the claw type rotor structure, the motor becomes highly compact which is essential for EV propulsion. Increasingly, by adjusting the field current and terminal voltage, the motor efficiency can be optimized throughout the whole operating range. Using the optimal efficiency control, the performances of the motor possesses a high potentiality for EV applications.

\section{APPENDIX}

TECHNICAL DATA OF THE MOTOR

$\begin{array}{ll}\text { Rated Power: } & 5 \mathrm{~kW} \\ \text { Rated Voltage: } & 270 \mathrm{~V} \\ \text { Base speed: } & 1000 \mathrm{rpm} \\ \text { No. of phases: } & 3 \\ \text { Stator } & \\ \text { No. of slots: } & 30 \\ \text { Outer diameter: } & 210 \mathrm{~mm} \\ \text { Inner diameter: } & 148 \mathrm{~mm} \\ \text { Length of core: } & 58 \mathrm{~mm} \\ \text { Winding type: } & \text { Double layer } \\ \text { No. of coils: } & 64 \\ \text { Rotor } & \\ \text { No. of poles: } & 10 \\ \text { Outside Outer diameter: } & 145.6 \mathrm{~mm} \\ \text { Outside Inner diameter: } & 118 \mathrm{~mm} \\ \text { Inside Outer diameter: } & 65 \mathrm{~mm} \\ \text { Inside Inner diameter: } & 38 \mathrm{~mm} \\ \text { Magnet material: } & \mathrm{Nd}-\mathrm{Fe}-\mathrm{B}\end{array}$

\section{REEERENCE}

[1] C.C. Chan, "An overview of electric vehicle technology", IEEE Proceedings, Vol. 81, 1993, pp. 1201-1217.

[2] T. M. Jahns, "Flux-weakening regime operation of an interior permanent magnet synchronous motor drive", IEEE Trans. on Ind Appl., Vol.IA-23, No.4, 1987, pp. 68-689.

[3] C. C. Chan, R. Zhang, K. T. Chau and J. Z. Jiang, "A novel permanent magnet hybrid motor for electric vehicles," Intemational Conference on Electrical Machine, 1995, Hangzhou, China.

[4] C. C. Chan, R. Zhang, K. T. Chau and J. Z. Jiang, "A novel brushless pm hybrid motor with a claw-type rotor topology for electric vehicles", Proceedings of 13th International Electric Vehicle Symposium (EVSI3), Osaka, Japan, October 1996, Vol. II, pp. 579-584.

[5] P. G. Handley and J. T. Boys, Space Vector Modulation: An Engineering Review. University of Auckland, New Zealand.

[6] Chung-Yuen Won, Sei-chan Kim and B. K. Bose, "Robust position control of induction motor using fuzzy logic control" IEEE Industry Application Society Annual meeting, 1993. Vol. 1, pp. 472-481. 